\title{
Teacher-student interaction in the context of higher education
}

\author{
Elena Makarova* \\ Ural State University of Economics, Department of Business Foreign Language, 620144 \\ Yekaterinburg, Russia
}

\begin{abstract}
The article addresses the issue of teacher-student relationship in Russian higher education environment. The aim of the study is to identify challenges and problems faced by first- and second-year Russian students in interaction with university teaching staff and consider ways of solving them. The paper presents the analysis of student survey results, which contained closed and open-ended questions. Quantitative and qualitative research methods, applied in the study, allowed to confirm students' needs for respectful attitude and teacher's support. Respectful teacher's attitude was found to be more significant for harmonizing classroom environment than teacher's ability to effectively transfer subject-related knowledge. Recommendations on establishing balanced teacher-student relationship and minimizing anxiety in higher education settings are given. The findings are in relation to teacher development programmes and their potential in providing teaching staff with pedagogical and psychological knowledge for establishing cooperative teaching and learning. Suggestions for further research including teacher-student interaction from teacher's perspective are outlined.
\end{abstract}

\section{Introduction}

Teacher-student interaction belongs to the topics which have increasingly attracted the attention of practitioners, methodologies and researchers in the last decades. Despite being in the centre of interest, the issue of relationship between university teachers and students in the context of higher education needs further development as constantly changing modern academic environment calls for new approaches to teaching and learning [1]. At present when most attention is paid to distance education challenges and development of teachers' technology-related skills, providing university staff with pedagogical and psychological knowledge can't be neglected. Through development programs university teachers can be assisted in responding to emerging professional needs, among which teacher-students relationships remain most important. Introducing innovative pedagogical approaches aimed at building a new type of teacher-student interaction can be a challenging task for those university teachers who lack pedagogical education. Methods and ways of building positive teacher-student communication undoubtedly deserve a place in professional development programs [2].

\footnotetext{
*Corresponding author: makarovayn@mail.ru
} 
Interaction of representatives of different generations, having different worldviews, beliefs and values, is likely to provoke conflicts. The gap between average age of a university teacher and a student may be around 23 years and can cause differences in students' and teachers' expectations for interactions during education process [3]. Obstacles emerging in teacher-student classroom communication demands from a university teacher the ability to handle difficult situations and adjust to constantly changing conditions. Modern teacher is expected to provide assistance in effective learning and build relationship based on trust.

The aim of the study is to determine challenges and problems in teacher-student interaction as seen by students of a Russian university. The objectives of the research are the following: on the basis of survey results to describe students' perception of university teachers' power and potential in creating an effective learning environment and reducing level of stress and anxiety experienced by students in the classroom; to identify students' needs related to teacher-student relationship.

Teacher-student interaction is considered to be among the most important relationship a person can encounter during his life [4]. As T. Farell [5] observes, building respectful relationship between teacher and student must be placed in the center of quality learning experiences. Teacher-student interaction can be developed and improved in different kind of activities. For example, E.K. Briody, E. Wirtz, A. Goldenstein and E.J. Berger explore faculty-student interactions and methods to mitigate faculty-student distance out of the classroom [6].

Modern authors consider the issue under discussion from opposite points of view: from the point of view of the teacher and from the student's perspective. As the paper focuses on learner's perception of teacher-student relationships, we will concentrate on the review of modern studies conducted in relation to students' understanding and interpretation of teacherstudent interaction. Research carried out from students' perspective, discusses the impact of teacher's professional, scientific and personal characteristics on teacher-student interaction [7]. Analysing these three areas of academic activities, the authors conclude that teacher's communicative skills help provide favourable learning environment and affect the quality of education. The literature review shows that most recent studies prove positive correlations between effective teacher-student interaction and growth of students' motivation and decrease of stress and anxiety level.

High-stress classroom atmosphere can originate from numerous factors, including a lack of teacher's support. Modern students experience stress and anxiety being in the classroom, which cannot but have negative impact nor only on academic performance of the students, but their psychological well-being [8]. The fact that many questions in this field remain unanswered and modern academic environment is observed to remain stressful, makes addressing the issue of teacher-student interaction and its further study relevant.

\section{Materials and methods}

It was decided that the best method to better understand students' perception of challenges in teacher-student interaction as well as teacher's potential in building an effective learning environment was to conduct a survey. The survey contained 13 questions, 6 of which belonged to the category of open-ended questions, the rest being close-ended ones. The participants were 38 first- and second-year Russian students, aged 18 and 19, who major in economics and management. Quantitative and qualitative methods were found effective for analysing students' survey responses and achieve the research aim.

\section{Results and discussion}


The analyses of students' responses can be divided into two parts: firstly, analysis of students' perception of the ability of the teacher to reduce student's anxiety and negative stress level; secondly, discussion of issues related to students' needs for respectful teacher's attitude and building cooperative relationship.

\subsection{Student's stress level and anxiety}

The percentage distribution of the answers given by the respondents to the question "Have you ever experienced anxiety or stress being in the classroom?" is presented in Figure 1.

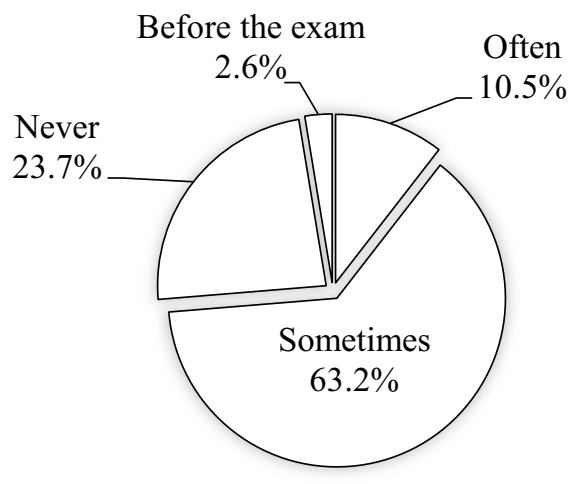

Fig. 1. Distribution of answers to the question "Have you ever experienced anxiety or stress being in the classroom?"

The pie-chart shows that more than $73 \%$ of the first- and second-year students have been under stress or felt anxiety. Though analysis of factors causing stress is beyond the scope of this study, the question "Do you feel afraid to ask questions in class?" was asked to see if communication with teachers, namely asking a question in the classroom, can cause negative stress or anxiety. Low percentage of students experience difficulties when asking their teacher questions - more than $86 \%$ of first- and second-year students do not consider it to be a challenge (Figure 2).

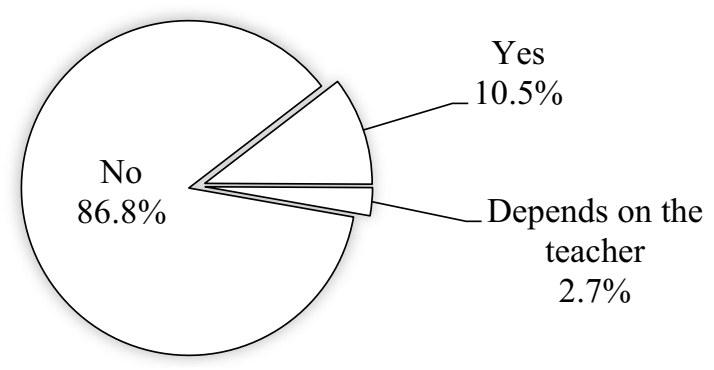

Fig. 2. Distribution of answers to the question "Do you feel afraid to ask questions in class?"

$92 \%$ of the students consider teachers to be able to reduce negative stress level in the classroom. These data indicate that the majority of the respondents are positive about teacher's ability to cope with classroom stressful situations and help students overcome anxiety (Figure 3).

Methods to handle stress in classroom settings are numerous. One of them suggests introducing into academic environment social-emotional learning [8]. It is proved to be efficient in combating anxiety and reduce negative stress level. Social-emotional learning impacts both students' academic success and their psychological well-being. 


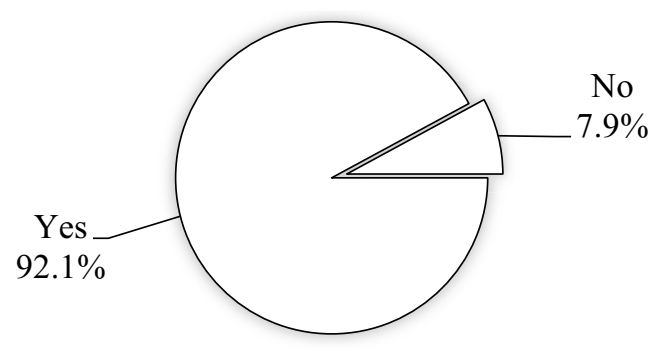

Fig. 3. Distribution of answers to the question "Can a teacher help reduce stress level in the classroom?"

Another pedagogical tool to establish teacher-student interaction based on trust, which enables efficient learning environment and helps minimize negative emotions, is teacher selfdisclosure [4], which implies revealing some information on teacher's personality even if this information is not related to the subject taught. Blended learning is also considered to be an effective method and can help reduce level of students' anxiety [9].

\subsection{Respectful relationship}

The second group of survey data relates to significance of establishing student-teacher respectful interaction. The analyses of respondents' answers showed that all the participants consider teacher's respectful attitude most important. According to students' responses, teachers can show they respect and value their students in many ways, for example by answering students' questions and not raising their voice. Among other answers are the following: objective evaluation of students' knowledge and performance, readiness to help, ability to listen and understand, equal attitude to all students, praising in the classroom, communicating with students, being a partner, giving a student a chance to express his point of view even if it's different from the teacher's opinion, being polite. Many answers refer to personal traits rather than professional characteristics of a teacher. The respondents were also required to compare the significance of teacher's respectful attitude with teacher's ability to transfer knowledge. Only few students view teacher's ability to explain the material in a simple way as more significant in comparison to respectful interaction. Some students opposed "communication with a student" to "giving a student subject-related knowledge", meaning by "communication" teacher's ability to encourage, inspire and praise. The data obtained by the survey confirmed the results of the research conducted by A.A. Fyodorov et al. [3]. Respectful attitude to students was valued higher than subject knowledge, which ranked second.

Students answers highlighted their need for respectful communication and studentteacher partnership in learning and teaching. These expectations along with high percentage of respondents who have experienced negative stress and anxiety in the classroom bring into discussion the importance of teachers' readiness to change their role from an information and knowledge transferor to a partner and a helper [10]. The necessity for establishing a learning partnership demands considering from teacher's perspective. Measuring teacher-student relationships from both perspectives can help better understand challenges and problems of teacher-student interaction [11].

\section{Conclusion}

The following conclusions can be drawn from the study. Most first- and second-year students who participated in the study have experiences negative stress or anxiety being in the 
classroom. About $10 \%$ of the respondents often find themselves in stressful situations being in academic environment. Teacher-student interaction did not prove to be a students' anxiety source as the majority of the respondents are not afraid of asking their teachers questions related to the subject. Over $90 \%$ of the participants perceive their teacher as a person who is able to help reduce level of stress in the classroom and improve learning environment. The second major finding concerns the relevance of establishing student-teacher respectful interaction to effectiveness of learning process. From the students' perspective respectful teacher's attitude is more significant in comparison to teacher's ability to transfer subjectrelated knowledge. The analysis of the survey answers revealed students' need for effective and respectful dialogue with teachers. According to the results obtained in earlier research, applying educational psychology in teaching and learning is not perceived by university teachers as their essential characteristics and task [12]. This calls for necessity of seeking new approaches to university teachers training, who should be prepared for initiating and establishing effective and respectful interaction with their students based on profound knowledge in methodology, psychology and pedagogy. University teachers without pedagogical training background can develop their pedagogical competence by participating in professional development programmes. Teachers involvement in these programmes can help introduce elements of educational psychology in teaching and learning and promote better understanding of students needs for teachers-student effective interaction and communication. Further research objectives can include the study of teacher-student interaction from Russian university teachers' perspective, as well as analyses of teachers' and students' readiness to establish learning partnership.

\section{References}

1. H. Gehlbach, M.E Brinkworth, A. Juraschek, Brit J Educ Psychol, 82, 690 (2012)

2. L. Claessens, J. van Tartwijk, A.C. van der Want, H. Pennings, Nico Verloop, Perry J. den Brok, T. Wubbels, J Educ Res, 110, 478 (2015)

3. A.A. Fedorov, E.Yu. Ilaltdinova, S.V. Frolova, Higher Education in Russia, 27, 28 (2018)

4. N. Safaei, M. Shahrokhi, Cogent Educ, 6, 1678231 (2019)

5. T. Farrell, ELT Journal, 69, 26 (2014)

6. E.K. Briody, E.Wirtz, A. Goldenstein, E.J. Berger, Eur J of Eng Educ, 44, 666 (2019)

7. F. Maleki, M.H. Talaei, S.R.M. Moghadam, S. Shadigo, H. Taghinejad, A. Mirzaei, J Clin Diagn Res, 11, 4 (2017)

8. S.L. Stocker, K.M. Gallagher, College Teaching, 67, 23 (2019)

9. P. Sarkar, S. Sharma, Int J Grid Distrib Comp, 13, 277 (2020)

10. M. Yusofi, S. Zarghami-Hamrah, Y. Ghaedy, A. Mahmudnia, Policy Futures in Education, 16, 147 (2017)

11. M.E. Brinkworth, J. McIntyre, A. Juraschek, H. Gehlbach, J Appl Dev Psychol, 55, 24 (2017)

12. I.E. Abramova, E.N. Makarova, Perspect Sci Educ, 44, 415 (2020) 